\title{
Research of Enterprise Financial Budget Management under Digital Environment
}

\author{
Guang Sen $\mathrm{Li}^{\star}$ \\ Qingdao Technological University(Linyi),China \\ liguangsen8888@126.com
}

Keywords: Digital environment; Financial budget; Budget management; Finance; problem

\begin{abstract}
Construction of digital and network-based environment makes enterprise gradually develop to information management. Financial budget management is an important part in modern enterprise management, which has positive influence on enterprise capital control and resource allocation. In the paper, enterprise financial budget management under digital environment is mainly studied. Problems in enterprise financial management in digital environment is briefly described, thereby proposing appropriate solution strategy, and promoting Chinese enterprises to enhance financial budget management in the digital environment.
\end{abstract}

\section{Introduction}

Digital and networked environment affects enterprise financial management in China with development and popularization of information technology. Budget management is regarded as one of important means in financial management, which plays an important role in modern enterprise management. Enterprise financial budget management has become one of important management modes for modern enterprise after development and evolution for many years. Enterprise financial budget management affects improvement and sustainable development of enterprise comprehensive ability to certain extent. Therefore, we should deepen recognition on enterprise financial budget management, and enterprises should pay sufficient attention to financial budget management.

\section{Overview of Enterprise Financial Budget Management under Digital Environment}

Characteristics of financial budget management. Enterprise financial budget management has strong binding and comprehensive features. Binding feature: it has strong binding feature in all procedures and links of enterprise financial budget management. Once budget management plan is established, it should not be randomly modified by any department and any employee. Enterprises should implement in strict accordance with budget management plan in the process of financial budget implementation. The enterprises should control and check according to enterprise budget indicators, thereby ensuring smooth completion of various work tasks in enterprise financial budget management. Comprehensive feature: business events related to objective realization can be managed in the form of currency during the process of enterprise financial budget management. Enterprises penetrate financial budget in all organization departments thereof, which can be reflected into event undertaken by all employees in the enterprise. Enterprises can reach overall management of enterprise financial budget through financial budget management.

Influence of digital environment on enterprise financial budget management. Digital environment refers that related information of enterprise business management is collected, sorted, integrated, etc. on the basis of network information technology and digital information technology. It is network information environment for fully utilizing these information resources. All enterprises can apply digital information technology in enterprise management activity. Digital environment can improve enterprise financial budget management level, thereby providing technical support for enterprise financial budget management. Enterprise information and resources can be digitized in digital environment, thereby facilitating enterprise financial budget management, and making 
enterprise financial budget management more scientific and effective. Digital information technology can be used for highly sharing and distributing enterprise information in real time. Financial budget management can be converted from traditional attention on post-control of budget into pre-budget and mid-control. All business of enterprise can be located in budget management system, which is beneficial for strengthening enterprise fund management, and enterprise activities are arranged in controlling scope of budget management. Enterprise budget management depends on digital environment, thereby improving backward information, incomplete information and other problems of traditional financial budget management in enterprise. Enterprise financial flow, management information flow and business flow can be fully integrated, thereby providing comprehensive and real information resources for financial management decision-making, and guaranteeing scientific and accurate enterprise financial budget management.

\section{Problems of Enterprise Financial Budget Management under Digital Environment}

Enterprise market competition is increasingly fierce in the digital environment. Modern enterprise development level is higher and higher, enterprise management should be reformed in order to stand out in market competition. Currently, many enterprises pay more and more attention to financial budget management, thereby enterprise financial budget management level in China is greatly improved, but there are still many problems, which seriously affect enterprise daily business activities and affect enterprise sustainable development. Enterprise financial budget management under digital environment mainly has the following problems:

Enterprise financial budget management is lack of integrated concept. Enterprises are lack of integrated concept aiming at financial budget management at present, and pay less attention to financial budget management in enterprise. They are lack of recognition and integrated concept mainly because some employees in the enterprise do not participate in financial budget management, for example, enterprise general manager does not participate in formulating financial budget management plan, other employees in the enterprise less participate in financial budget management, and they believe that enterprise financial budget management should be undertaken by finance department. Enterprises do not combine all departments, organizations, units and budget management stages, and all department units have low participation. Enterprise financial budget has a very important part of enterprise fund management. It is a long-term process to formulate scientific and effective financial budget system. Actual condition of enterprise budget management in China shows that Chinese enterprises are generally lack of financial budget management awareness, thereby seriously affecting optimization configuration of enterprise financial budget management personnel and realization of enterprise decision-making objectives. Enterprises are lack of integrated concept of financial budget management, and enterprise financial budget management can not reach desired effect.

Enterprise financial budget management is lack of strategy orientation. Since enterprise long-term development strategy is not considered in budget management at present, enterprises will pay attention to short-term interests, and ignore long-term goals, thereby short-term budget targets can not adapt to long-term development strategy of enterprises. Budgets in all stages are poorly converged, which are not beneficial for driving realization of enterprise long-term objectives. Enterprise budget targets are connected with engagement term performance goals of business operators, thereby leading to profit increase phenomena in the engagement term. Obviously, the business results are not beneficial for long-term development of enterprises. For example, since enterprises strives to list as soon as possible, budget indicators formulated by enterprises almost belong to indicators in the aspect of finance. In addition, indicators only express financial objectives which are expected for completion within one year in the future. They can not affect the effort that enterprise must make in internal flow, employees and system in order to reach the financial objective. In addition, design of enterprise budget and other non-financial indicators only lie in level of department, and a financial budget indicator system penetrating throughout the enterprise is not formed. 
Disconnection among Budget Execution Result Assessment, Evaluation, Reward and Punishment. Budget execution result assessment, evaluation, reward and punishment form the last link of budget management, which belongs to necessary measure for exerting binding and incentive roles of budget. Some enterprises do not implement budget execution result assessment, evaluation, reward and punishment in performance evaluation measures, or the reward and punishment system is unreasonable. Responsible unit and principals are evaluated with budget standard in the process of enterprise budget management. When they are punished or rewarded according to assessment results, the assessed parties pay more attention to influence of objective factors on activity performance. Objective reasons are deliberately avoided, the assessment parties also mix much personal feelings to evaluate the assessed parties, therefore the assessment process is lack of objectivity, fairness, science and rationality.

\section{Suggestion of Strengthening Enterprise Financial Budget Management}

Enterprise financial budget management approach is gradually changing, and the budget management concepts are also greatly changed due to influence of digital environment. Enterprise can be developed rapidly and stably through reinforcing enterprise financial budget management. Enterprise should adopt scientific and effective measures aiming at problems in enterprise financial budget management in China, thereby improving enterprise financial budget management, enhancing enterprise financial budget management level, and increasing the competitiveness of enterprises. Therefore, the following recommendations should be proposed aiming at problems in enterprise financial budget management analyzed in the paper:

Establishing overall concept of financial budget management. Enterprises should strengthen learning of financial budget management overall concept, deepen recognition on financial budget management, pay attention to enterprise financial budget integrated management, refine all financial budget management indicators in details, determine and all responsibility units of all financial budget management in enterprise, objectives of enterprise financial budget management are refined, thereby dividing objectives of financial budget management into all departments, determining authority and responsibility scope of all employees in enterprise, and formulating corresponding reward and punishment system. Staff in each department can enjoy clear rights and responsibilities, thereby ensuring that enterprises can smoothly construct tight financial budget management organization. Supervision on employee financial management budget objective implementation can be reinforced, process management is intensified, integrated concept of enterprise financial budget management is improved for enhancing enterprise budget management level.

Regarding market and enterprise development strategies as financial budget management guidance. Budget management can digitally reflect planning objectives, which acts as effective means for implementing enterprise development strategies. Therefore, concept of regarding market and enterprise development strategy as foundation is determined, daily budget management is regarded as cornerstone for realizing long-term development strategy. Before financial budget management is implemented in enterprise, enterprise resources and market situation should be carefully analyzed, medium and long-term development objectives of the enterprise should be made clear, which are regarded as foundation for formulating budget, budgets in all stages can be smoothly connected. After enterprise strategic objectives are determined, enterprise annual budget should be formulated according to annual strategic objectives. Meanwhile, influence of next year enterprise resources, market changes and other factors should be considered, budget indicators of next year are adjusted in time. Therefore, randomness and blindness of budget indicators can be reduced, situation of making decision by superior level and implementing passively by subordinates can be avoided, thereby effectively improving management efficiency.

Improving Budget Indicator System and Innovating Budget Preparation Model. Generally, enterprises, especially group enterprises, have complex business. It is not enough to formulate financial indicators only. Production and business indicators suitable for the departments should be 
formulated with employees from all departments as main body on the basis of establishing special budget team. Meanwhile, financial personnel should sum up all important indicators, deeply study internal relationship among all indicators, and construct perfect indicator system. In terms of budget model, financial personnel formulated, superior department approved, and business department implemented in the past, the situation should be changed. Budget mode from top to bottom, from bottom to top and combination both bottom and top should be adopted under the precondition of rational budget indicator design and budget formulation department composition. Namely, enterprise management personnel should propose enterprise budget annual integrated objectives and branch objectives of all responsible departments according toe enterprise strategic objectives. Then, all departments should formulate business plan of own departments and report it to budget formulation team according to actual condition, the budget team should formulate budget according to business plan of all departments, who is responsible for communication and coordination among all departments. The team should discus with enterprise superior level and department representatives aiming at special events, thereby finally formulating budget.

Establishing sound financial budget management organization and institutional system. Enterprise financial budget management can be successfully implemented by scientific budget management organization. Budget management committee must be established, budget management leadership team and budget management committee are the highest decision-making and regulatory agencies to implement comprehensive budget management. Budget drafts of all units can be considered in the form of budget meetings. Budget management committee can develop clear, practical and feasible budget overall policies on the basis of scientific and sufficient predication and decision-making, and the policies can be released to all budgeting units; Budget management committee and budget management leadership team are mainly responsible for releasing budget control objectives, considering budget preparation policies, procedures and methods, and proposing suggestions and recommendations for correcting budget plan.

\section{Summary}

In recent years, enterprise financial budget management is developed fast in China. Enterprise financial budget management is a tool for enterprise management, which also belongs to a mechanism in enterprise management. It has irreplaceable effect in enterprise management, which can improve enterprise operation management efficiency and enterprise economic efficiency. Therefore, Chinese enterprises should strengthen financial budget management development, and establish scientific and effective budget management mechanism under digital context, thereby improving enterprise financial budget management level.

\section{References}

[1]. Chuanyan LIU. The function of finance budget management in business, J.The research of finance and accountant. 2011,(18):39-43.

[2]. Jinsong WEI. The important function of finance budget in risk controlling, J. Auditing monthly magazine. 2008,(09):27.

[3]. Peng HAN, Jiahai Tang. The confusion and thought of finance budget, J. Friend of accountant. 2006,(03):89.

[4]. Hongsheng XIE. A Research on the Financial Budget Management of the Local Tax Branch. Hebei University,2010.

[5]. Wenqing JIANG. The role and application of finance budget in business management, J. Communication of finance and accountant. 
[6]. Chunxi YANG. Study on power enterprise financial budget execution problems. Sichuan Water Conservancy Press, Chengdu, 2012.

[7]. Xishan ZHAO. Full-course management of finance budget in higher vocational colleges, J. Finance and accountant monthly magazine. 2009,(18):63-65.

[8]. Xudong YIN. Creation and discussion of finance budget management in business, J. Financial community. 2012,(10):197.

[9]. Jingxiang WANG. Excel Model of financial budget in small business--The reverse thinking of "From finance indicators to finance budget", J. Finance and accountant monthly magazine. 2013,(09):79-81.

[10]. Weidong WANG. The execution and control of overall budget management in Enterprise. International Business Accounting, J. 2007,(6):18-19. 